\title{
Interactions of Water Soluble Porphyrin Derivatives with a Zwitterionic Polypeptide
}

\author{
Yasumasa FukushimA \\ Research \& Development Center, Unitika Ltd., 23 Kozakura, Uji, Kyoto 611, Japan
}

(Received June 22, 1995)

\begin{abstract}
Complex formation of water-soluble porphyrin derivatives with the $\beta$-sheet structure of zwitterionic poly(Glu-Val-Lys-Val) was studied by absorption spectra and circular dichroism measurements. Interaction of tetrakis(4- $N$-methylpyridyl)porphine (TMPyP) with the polypeptide is not observed, whereas tetraphenylporphinetetrasulfonic acid (TPPS) interacts when TPPS exists as a diacid species. Positive charges in porphyrin center for the diacid species may play an important role in complex formation. The monomeric TPPS diacid species aggregates by the addition of the polypeptide, and two types of aggregation species with $S$-chiral conformation are observed. From $[\mathrm{P}] /[\mathrm{D}]=1$ to 5 , one aggregation species has absorption bands at $489 \mathrm{~nm}$ and $701 \mathrm{~nm}$, which increases with $[\mathrm{P}] /[\mathrm{D}]$ ratios or decreasing $\mathrm{pH}$. Both the monomer and aggregation species can more effectively bind to the polypeptide with decreasing $\mathrm{pH}$. The other aggregation species is present above $[\mathrm{P}] /[\mathrm{D}]=10$, it increases with increasing $[\mathrm{P}] /[\mathrm{D}]$. Interconversion between two types of aggregation species would take place from $[\mathrm{P}] /[\mathrm{D}]=5$ to 10 . The $\beta$-sheet content of the polypeptide is kept constant above $[\mathrm{P}] /[\mathrm{D}]=2$, but increases slightly around $[\mathrm{P}] /[\mathrm{D}]=1$.

KEY WORDS Zwitterionic Polypeptide / Porphyrin Derivatives / Induced Circular Dichroism / Interconversion between Aggregations / Electrostatic Interactions /
\end{abstract}

The metal complexes of porphyrin compounds are central to primary charge separation in photosynthetic reaction centers as well as oxygen transport in red blood cells when bound to specific proteins as found in nature. ${ }^{1,2}$ The study of interactions between porphyrin derivatives and synthetic peptides is an approach to the determination of spatial arrangement and binding sites of the porphyrin derivatives bound to numerous macromolecules of biological interest.

When some symmetric dye molecules interact with biopolymers such as polypeptides, polysaccharides, and polynucleic acids adopting specific regular conformations, they exhibit induced optical activity in the region corresponding to their characteristic absorption bands of the bound dye. ${ }^{3}$ On the other hand, these symmetric dyes are optically inactive when free. Many investigators have studied the interaction of $\alpha$-helical conformation of poly(L-glutamic acid) with some cationic dyes or various secondary conformations of poly $(\mathrm{L}-$ lysine) with some anionic dyes. ${ }^{4-6}$

Optical activity can be observed by circular dichroism (CD) measurement, in which circular dichroic bands appear at the region of absorption bands where there are extrinsic Cotton effects. Bound dyes to polypeptides can induce $\mathrm{CD}$ by three possible mechanisms: (1) inherent dissymmetry of the dye, (2) coupled oscillator interactions between the bound dye and groups on the polypeptide, and (3) mixing of excited states of differing symmetry within the dye under the influence of an electrostatic field produced by the binding sites of the polypeptide. Because porphyrin molecules are planar chromophores, their CD can be induced only through the mechanisms (2) and (3).

The porphyrin molecule is a large cyclic 
compound having a conjugate $18-\pi$-electron system, and four nitrogen atoms at the center of porphine ring can chelate various metals. Since the porphine ring is an anion having a charge of -2 , a porphyrin without a metal is electrically neutral by containing two hydrogen ions in the central region. Porphyrin derivatives give rise to two main absorption $\mathrm{Q}$ and Soret bands. These bands exhibit absorption maxima at $500-600 \mathrm{~nm}$ in the visible region and $400 \mathrm{~nm}$ in the vicinity of ultraviolet region, respectively. ${ }^{7,8}$ Because most natural and synthetic porphyrins show insufficient solubility in aqueous solution, several water-soluble porphyrin derivatives have been prepared by introducing charged groups into the porphine molecule for investigation of their behavior in aqueous solution. ${ }^{9,10}$ Interactions of watersoluble porphyrin derivatives with watersoluble biopolymers have been studied extensively. ${ }^{11-13}$

Poly(Glu-Val-Lys-Val) can form an unusually stable $\beta$-sheet conformation in aqueous solutions in the $\mathrm{pH} 2.0$ to 12.0 region by ionic self-complementary interaction between a glutamic acid and a lysine residue in addition to hydrophobic interactions between valine residues as reported previously. ${ }^{14}$ The $\beta$-sheet
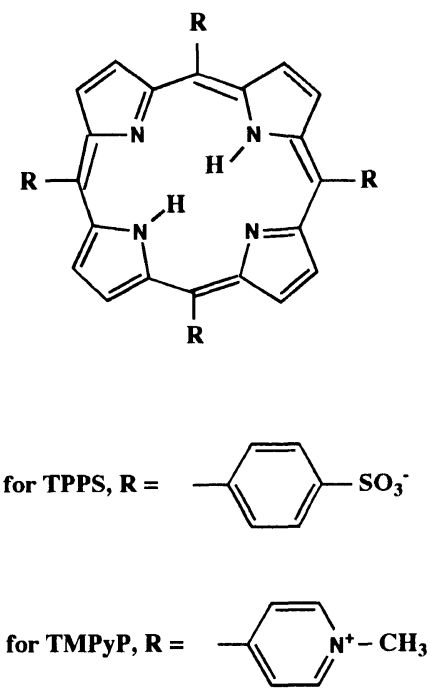

Figure 1. Structures of TPPS and TMPyP. conformation is stable at $\mathrm{pH} 7$ even in the presence of some salts and denaturation agents. The polypeptide is an amphiphilic compound including both negatively charged and positively charged amino acid residues, to which may become attached both anionic and cationic dye chromophores.

The present work investigates complexes of water-soluble porphyrin derivatives and $\beta$ sheet conformation of poly(Glu-Val-Lys-Val). The symmetric porphyrin derivatives in this study are a porphine-meso-tetra(4-benzenesulfonate) salt (TPPS) ${ }^{10}$ and a porphine-mesotetra(4- $N$-methylpyridinium) salt (TMPyP), ${ }^{9}$ which are anionic and cationic, respectively, and exhibit high solubility in aqueous solution. Figure 1 illustrates the structures of TPPS and TMPyP. TPPS can be expected to interact with an $\varepsilon$-amino group of the lysine residue of the polypeptide, while TMPyP may interact with a $\gamma$-carboxylic acid group of the glutamic acid residue. TPPS and TMPyP tend to stack spontaneously in aqueous solution to form dimers with $\pi-\pi$ interactions, the binding constants for dimerization being $10^{4}-10^{7}$ $\mathrm{mol}^{-1} \mathrm{dm}^{3}{ }^{15,16}$ Each porphyrin derivative can bind to the polypeptide in porphyrin monomeric and/or dimeric species.

Porphyrin-polypeptide complexes may induce in change absorption spectra and optical activity. Therefore, the absorption spectra and CD spectra of the aqueous solutions of the complexes were measured at different $\mathrm{pH}$ and different polypeptide[P]-to-porphyrin[D] residue mixing ratios, $[\mathrm{P}] /[\mathrm{D}]$ for investigation of complex formation, bound form and interconversion of porphyrin molecules under various experimental conditions. Poly(GluVal-Lys-Val) adopts the $\beta$-sheet conformation under all experimental conditions.

\section{EXPERIMENTAL}

\section{Materials}

Poly(Glu-Val-Lys-Val) was synthesized according to the method in the previous paper. ${ }^{14}$ 
The intrinsic viscosity was $0.114 \mathrm{dlg}^{-1}$ in dichloroacetic acid and corresponds to a molecular weight of 14000 if we apply the relationship proposed by Doty et al. ${ }^{17}$ The size exclusion chromatogram showed molecular weight to be 14400 .

Tetraphenylporphinetetrasulfonic acid disulfonic acid salt tetrahydrate (TPPS) and tetrakis(4- $N$-methylpyridyl)porphine tetra( $p$ toluenesulfonate) (TMPyP) were purchased from Dojindo Laboratories and used without further purification.

A stock solution of poly(Glu-Val-Lys-Val) was prepared at the residue molar concentration $4.72 \times 10^{-2} \mathrm{M}$ based on total moles of the glutamic acid or the lysine residue, and dissolved in deionized distilled water. Porphyrin was dissolved in water to prepare a stock solution of $6.67 \times 10^{-4} \mathrm{M}$. A porphyrin-polypeptide mixture solution was prepared by adding porphyrin dye solution to the polypeptide solution to make the desired porphyrinpolypeptide molar ratio, $[\mathrm{P}] /[\mathrm{D}]$, where $[\mathrm{P}]$ is the residue molar concentration of the polypeptide and [D] is the molar concentration of TPPS or TMPyP, and $\mathrm{pH}$ of the solution was adjusted to the desired value by $0.1 \mathrm{~N}$ $\mathrm{HCl}$ or $0.1 N \mathrm{NaOH}$ for absorption and CD spectra measurements. $[\mathrm{P}] /[\mathrm{D}]$ was varied from 0 to 20 , but the final concentration of the porphyrin was fixed at $6.67 \times 10^{-5} \mathrm{M}$. pH was varied from 2.0 to 12.0 . The spectra of all mixture solutions were measured within an hour after preparation.

\section{Measurements}

Absorption spectra of the solutions were measured on a Hitachi U-4000 Spectrophotometer over $750-350 \mathrm{~nm}$ at room temperature, using a quartz cuvette of $0.1 \mathrm{~cm}$ pathlength. CD spectra of the solutions were obtained in the range of 750 to $350 \mathrm{~nm}$ at $20^{\circ} \mathrm{C}$ under a constant flow of nitrogen on a Jovin Ivon CD6 spectropolarimeter equipped with an interface and personal computer using a quartz cuvette of $0.1 \mathrm{~cm}$ pathlength. The in- struments were calibrated with an aqueous solution of ammonium $d$-camphorsulfate. ${ }^{18}$ Absorption and $C D$ spectra were expressed as the molar extinction coefficient $[\varepsilon]$, normalized to decimeter cube units per mol centimeter, and the molar ellipticity $[\theta]$, which was normalized to units of degrees centimeter squared per decimole, based on the molar concentration of total added porphyrin. $\mathrm{pH}$ was measured with a Horiba $\mathrm{pH}$ meter F-16 before CD measurement.

\section{RESULTS}

\section{Absorption Spectra of TPPS in the Absence of Poly (Glu-Val-Lys-Val)}

TPPS exists as a free base species in neutral solution, while TPPS forms a diacid species in acidic solution. The free base species contains two hydrogens at the center of the molecule, and the diacid species contains four hydrogens at the central region. $\mathrm{p} K_{\mathrm{a}}$ of TPPS (TPPS + $2 \mathrm{H}^{+} \leftrightarrow \mathrm{H}_{2} \mathrm{TPPS}^{2+}$ ) is approximately $4.8 .{ }^{10}$ After making a neutral solution of TPPS below $\mathrm{pH} 5$, the solution changed in color from pink to green. Figure 2 illustrates the absorption spectra of the solutions of TPPS at different $\mathrm{pH}$. Absorption spectrum of TPPS in neutral aqueous solution at $6.67 \times 10^{-5} \mathrm{M}$ has bands at 416 (Soret), 517, 553, 582, and $634 \mathrm{~nm}$ (Q band) as well as a weak shoulder at $393 \mathrm{~nm}$. The Soret bands of porphyrins are absorption bands at two different wavelengths, and these two components are expressed as $\mathbf{B}_{x}$ and $\mathbf{B}_{\boldsymbol{y}}$ components. ${ }^{19,20}$ The $\mathrm{B}_{x}$ component becomes polarized parallel to the line connecting hydrogen atoms of opposing pyrrole groups, namely, to the $\mathrm{H}-\mathrm{H}$ axis, whereas the $\mathrm{B}_{y}$ component polarizes perpendicular to the $\mathrm{H}-\mathrm{H}$ axis. In general, the $\mathrm{B}_{x}$ component is a longer wavelength and has more molar extinction coefficient than the $\mathrm{B}_{y}$ component when porphyrins are free base species. It can be therefore presumed that the Soret bands at $416 \mathrm{~nm}$ and $393 \mathrm{~nm}$ correspond to the $B_{x}$ and $\mathrm{B}_{y}$ components. As the concentration of the 

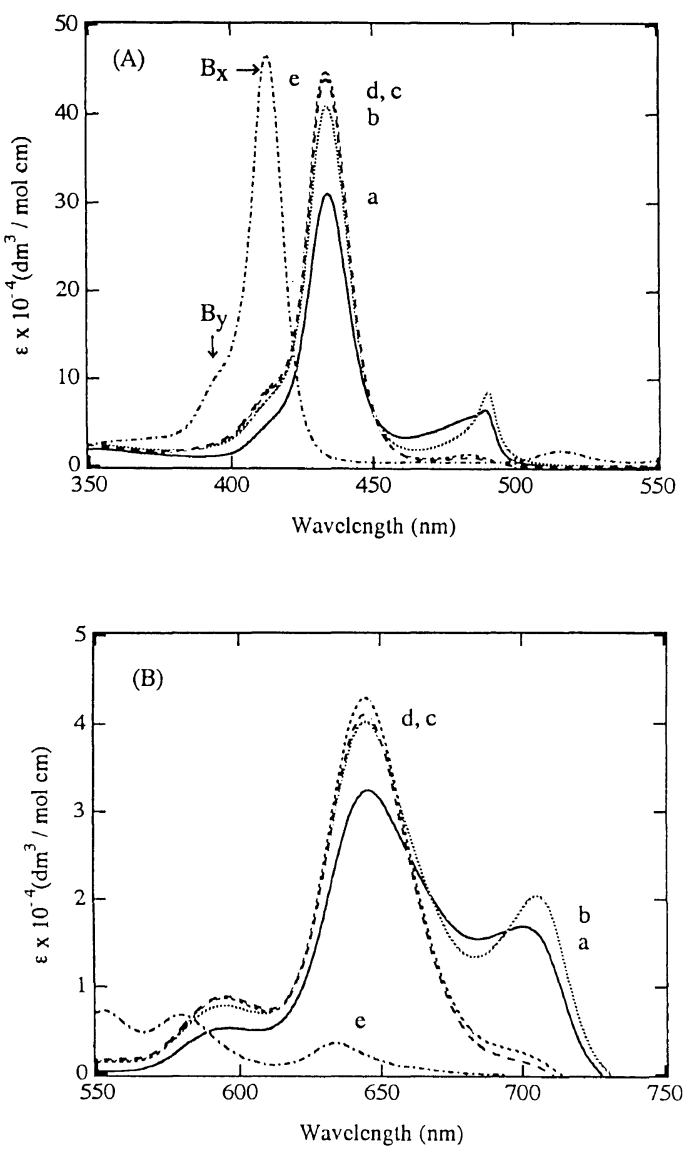

Figure 2. Absorption spectra of $6.67 \times 10^{-5} \mathrm{M}$ TPPS in aqueous solution in the absence of poly(Glu-Val-Lys-Val) at different pH. a, $\mathrm{pH} 2.0 ; \mathrm{b}, \mathrm{pH} 3.5 ; \mathrm{c}, \mathrm{pH} 4.0$; d, pH 4.5; $\mathrm{e}, \mathrm{pH} 7.0$. (A) wavelength, $350-550 \mathrm{~nm}$; (B) wavelength, $550-750 \mathrm{~nm}$.

porphyrin increases, the apparent molar absorptivities of all bands decrease in magnitude, while the Soret band shifts to a shorter wavelength and the $\mathrm{Q}$ band shifts to a longer wavelength. ${ }^{15}$ These concentration dependent spectral changes have been reported and are attributed the aggregation of TPPS in aqueous solution. ${ }^{21}$

The absorption spectrum of $6.67 \times 10^{-5} \mathrm{M}$ TPPS in aqueous solution at $\mathrm{pH} 4.0$ has bands at 434 (Soret), 593 and $644 \mathrm{~nm}$ (Q band). These bands are assigned to a monomeric TPPS diacid species. Below pH 3.5, new absorption bands at $489 \mathrm{~nm}$ and $701 \mathrm{~nm}$ are observed in addition to those of the diacid species. It is presumed that these new bands are assigned to the aggregation (a dimer or an aggregate) of a diacid species. It was reported that phenyl groups, are almost perpendicular to the porphyrin ring, which rotated toward the porphyrin plane in the diacid species, and this TPPS aggregation may be a face-to-face structure with $\pi-\pi$ interactions, so that this rotation would allow closer interactions between two porphyrins. ${ }^{10}$

Below pH 5.0, absorption spectra of TPPS at $6.67 \times 10^{-5} \mathrm{M}$ in aqueous solution are dependent on $\mathrm{pH}$, while independent of $\mathrm{pH}$ above pH 5.0 (data not shown). As $\mathrm{pH}$ decreases below pH 3.5, absorption bands at $434 \mathrm{~nm}$ and $644 \mathrm{~nm}$ decrease, whereas intensities of the absorption bands at $489 \mathrm{~nm}$ and $701 \mathrm{~nm}$ increase. These results indicate that a monomeric TPPS diacid species aggregates to a dimer or an aggregated TPPS diacid species with decreasing $\mathrm{pH}$. The aggregation may be caused by electrostatic attractive interactions between negatively charged sulfonate groups and a positively charged porphyrin center.

No dichroic bands of TPPS were observed in the absence of poly(Glu-Val-Lys-Val) under any experimental conditions (data not shown).

\section{Dependence of Spectra of TPPS with Poly(Glu- Val-Lys-Val) on $\mathrm{pH}$}

Figures 3 and 4 illustrate absorption spectra and $C D$, respectively, of solutions of TPPS mixed with poly(Glu-Val-Lys-Val) of [P]/ $[D]=2$ at different $\mathrm{pH}$. Table I gives values of absorption parameters and induced CD parameters for the TPPS-poly(Glu-Val-LysVal) system.

From pH 4.0 to 4.5 , two absorption bands at $488 \mathrm{~nm}$ and $703 \mathrm{~nm}$ appeared by the addition of poly(Glu-Val-Lys-Val) although these bands were not observed in the absence of the polypeptide. This indicates that poly(Glu-ValLys-Val) induces to aggregate a TPPS diacid species by electrostatic interactions between the polypeptide and the TPPS diacid species. 

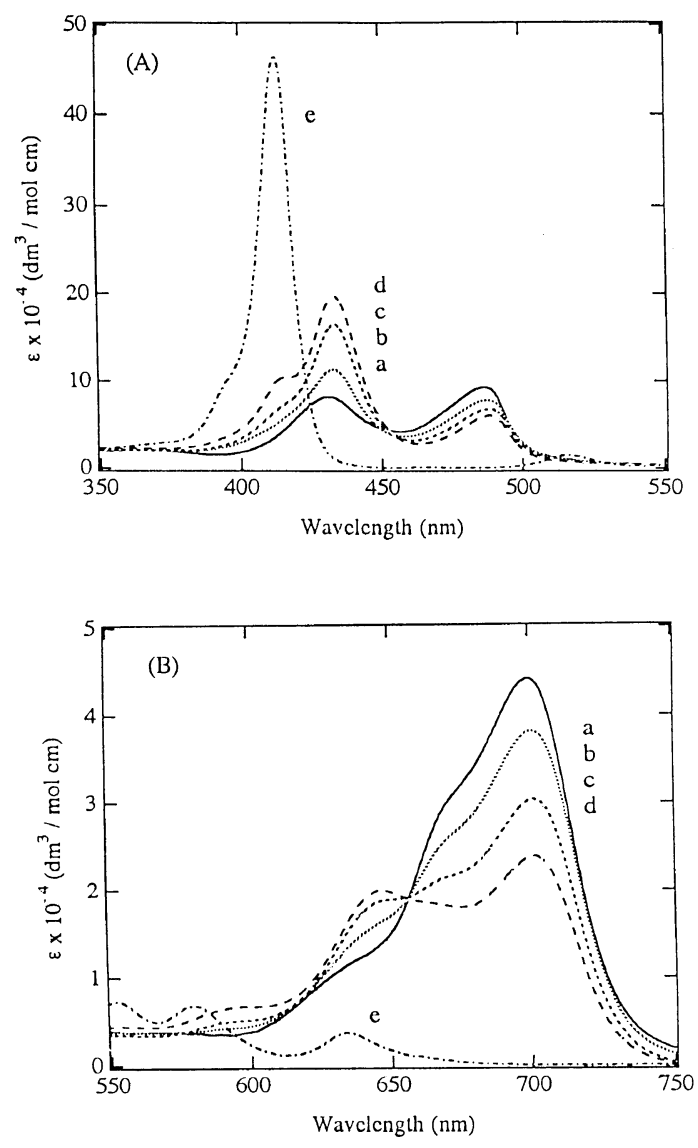

Figure 3. Absorption spectra of $6.67 \times 10^{-5} \mathrm{M}$ TPPS in aqueous solution in the presence of poly(Glu-Val-Lys-Val) at different $\mathrm{pH}$. $[\mathrm{P}] /[\mathrm{D}]=2 \mathrm{a}, \mathrm{pH} 2.0 ; \mathrm{b}, \mathrm{pH} 3.5 ; \mathrm{c}, \mathrm{pH}$ $4.0 ; \mathrm{d}, \mathrm{pH} 4.5$; e, pH 7.0. (A) wavelength, $350-550 \mathrm{~nm}$; (B) wavelength, $550-750 \mathrm{~nm}$.

The aggregation may result from suppression of electrostatic repulsion between sulfonate groups of two diacid species by $\varepsilon$-ammonium groups of lysine residues.

From pH 2.0 to 4.5 , in the Soret region, two absorption bands are observed at $434 \mathrm{~nm}$ and $488 \mathrm{~nm}$, and the isobestic point is located at $452 \mathrm{~nm}$. For Q bands, two absorption bands exist around $646 \mathrm{~nm}$ and $703 \mathrm{~nm}$, and the isobestic point is observed at $655 \mathrm{~nm}$. The absorbance at $434 \mathrm{~nm}$ and $646 \mathrm{~nm}$ decrease in magnitude with decreasing $\mathrm{pH}$, whereas absorbance at $488 \mathrm{~nm}$ and $703 \mathrm{~nm}$ increases in magnitude with decreasing $\mathrm{pH}$. A monomeric

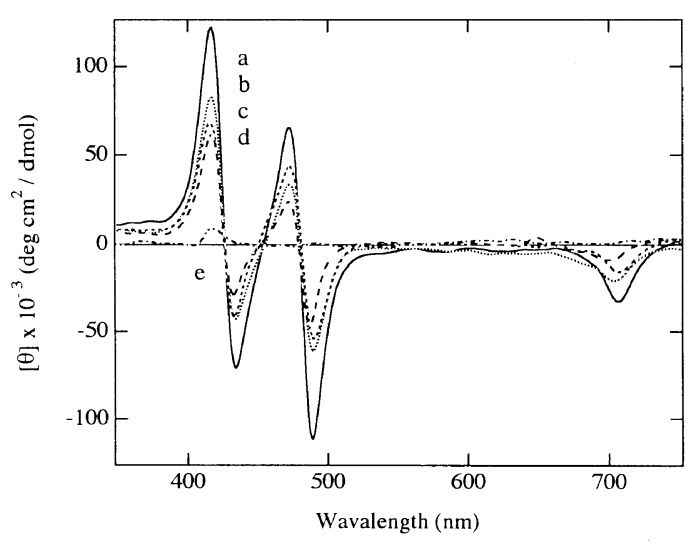

Figure 4. $\mathrm{CD}$ spectra of $6.67 \times 10^{-5} \mathrm{M}$ TPPS in aqueous solution in the presence of poly(Glu-Val-Lys-Val) at different $\mathrm{pH}$. $[\mathrm{P}] /[\mathrm{D}]=2$ : $\mathrm{a}, \mathrm{pH} 2.0 ; \mathrm{b}, \mathrm{pH} 3.5$; $\mathrm{c}, \mathrm{pH} 4.0$; d, $\mathrm{pH} 4.5$; e, $\mathrm{pH} 7.0$.

TPPS diacid species may thus aggregate with decreasing $\mathrm{pH}$ because increase of positively charged porphyrin center with decreasing $\mathrm{pH}$ results in enhancement of electrostatic attractive interactions between sulfonate groups and the TPPS center for aggregation.

A shoulder was observed at $415 \mathrm{~nm}$ at $\mathrm{pH}$ 4.5 , and assigned to a TPPS monomer in a free base species. Because $\mathrm{pH} 4.5$ is close to $\mathrm{p} K_{\mathrm{a}}$ for formation of the TPPS diacid species, TPPS would exist as a mixture of a diacid and free base species.

The induced CD bands are slightly observed above $\mathrm{pH}$ 5.0, whereas below $\mathrm{pH} 4.5$, five induced $\mathrm{CD}$ bands appear. Below $\mathrm{pH} 4.5$, at least two dichroic bands are associated with each TPPS absorption band at $434 \mathrm{~nm}$ and $489 \mathrm{~nm}$. Both bands are a pair of positive and negative dichroic bands, the positive one is at a shorter wavelength and the negative one, at a longer wavelength. The induced pair $C D$ bands at $417 \mathrm{~nm}$ and $434 \mathrm{~nm}$ may be attributed to the absorption band at $434 \mathrm{~nm}$, is assignable to the monomer TPPS diacid species. Because the induced CD bands of TPPS are not observed in the absence of poly(Glu-Val-LysVal), these induced CD bands are caused by interactions between a TPPS diacid species and the polypeptide. The splitting of the absorption 
Table I. Absorption and CD parameters of TPPS in the presence of poly(Glu-Val-Lys-Val) ${ }^{\mathrm{a}}$

\begin{tabular}{|c|c|c|c|c|c|}
\hline & $\mathrm{pH} 2.0$ & $\mathrm{pH} 3.5$ & $\mathrm{pH} 4.0$ & $\mathrm{pH} 4.5$ & $\mathrm{pH} 7.0$ \\
\hline \multirow{5}{*}{$\begin{array}{c}\lambda, \mathrm{nm} \\
\left(10^{-3} \varepsilon, \mathrm{M}^{-1} \mathrm{~cm}^{-1}\right)\end{array}$} & $433(82.2)$ & 433 (113) & $434(156)$ & 415 (114) & $413(464)$ \\
\hline & $487(93.0)$ & $487(78.2)$ & $489(60.2)$ & 433 (197) & $515(18.3)$ \\
\hline & $672(30.4)$ & $646(16.4)$ & $644(22.6)$ & $488(60.5)$ & $554(8.6)$ \\
\hline & $702(44.2)$ & $672(26.1)$ & $701(27.5)$ & $646(19.9)$ & $580(8.3)$ \\
\hline & & $702(38.2)$ & & $702(23.8)$ & $632(1.2)$ \\
\hline \multirow{5}{*}{$\begin{array}{c}\lambda, \mathrm{nm} \\
\left(10^{-3}[\theta],\right. \\
\left.\operatorname{deg} \mathrm{cm}^{2} \mathrm{~d} \mathrm{~mol}{ }^{-1}\right)\end{array}$} & 417 (122) & $417(82.8)$ & $416(68.5)$ & $417(61.5)$ & $417(12.2)$ \\
\hline & $434(-70.9)$ & $434(-43.0)$ & $433(-41.3)$ & $433(-29.1)$ & \multirow{9}{*}{0.03} \\
\hline & $472(65.4)$ & $473(43.8)$ & $472(43.7)$ & $472(24.2)$ & \\
\hline & $489(-112)$ & $489(-60.9)$ & $490(-54.0)$ & $487(-47.0)$ & \\
\hline & $706(-32.7)$ & $704(-21.0)$ & $706(-15.8)$ & $701(-9.2)$ & \\
\hline \multirow{5}{*}[\theta]{$/ \varepsilon$} & 1.48 & 0.73 & 0.44 & 0.31 & \\
\hline & -0.86 & -0.55 & -0.26 & -0.18 & \\
\hline & 0.70 & 0.56 & 0.73 & 0.40 & \\
\hline & -1.20 & -0.77 & -0.90 & -0.78 & \\
\hline & -0.74 & -0.55 & -0.57 & -0.39 & \\
\hline
\end{tabular}

${ }^{\mathrm{a}}[\mathrm{P}] /[\mathrm{D}]=2 ;[\mathrm{D}]=6.67 \times 10^{-5} \mathrm{~m}$.

band at $434 \mathrm{~nm}$ suggests that two monomeric TPPS diacid species bind consecutively to different sites on the polypeptide and are electronically coupled together.

The induced CD bands at $472 \mathrm{~nm}$ and $489 \mathrm{~nm}$ are assigned to aggregation of the TPPS diacid species. The splitting of the absorption band at $489 \mathrm{~nm}$ into two CD bands would be caused by exciton coupling of a dimeric or aggregated TPPS. The induced CD bands are a positive band at shorter wavelength and negative band at longer wavelength, show that the aggregation is in S-chiral conformation according to the exciton chirality method. ${ }^{22,23}$

The induced CD band around $705 \mathrm{~nm}$ may be associated with the absorption band at $701 \mathrm{~nm}$, which is assigned to aggregation of the TPPS diacid species.

TPPS in free base species would not interact with the polypeptide from no observation of an induced CD band and no difference of absorption spectra of TPPS between in the presence of the polypeptide and in the absence.

These results indicate that sulfonate groups cannot simply electrostatically interact with e-ammonium groups of lysine residues, and positive charges in the center of TPPS may require TPPS to bind to the polypeptide. The positive charges of a TPPS diacid species may interact with $\gamma$-carboxylic groups of glutamic acid of the polypeptide for formation of the TPPS-poly(Glu-Val-Lys-Val) complex.

Figure 5 shows the dependence of $[\theta] / \varepsilon$ at $[\mathrm{P}] /[\mathrm{D}]=2$ on $\mathrm{pH}$. The absolute value of $[\theta] / \varepsilon$ assigned to a monomeric TPPS diacid species decreases with increasing $\mathrm{pH}$. The absolute value of $[\theta] / \varepsilon$ assigned to aggregation of the TPPS diacid species decreases with increasing $\mathrm{pH}$ except $\mathrm{pH}$ 4.0. Because the dissymmetric factor, $[\theta] / \varepsilon$, increases with decreasing $\mathrm{pH}$, positive charges in the center of TPPS diacid species may play an important role in interactions between TPPS and poly(Glu-Val-LysVal).

In the range of all experimental $\mathrm{pH}$, because the intensity of the residue ellipticity at $217 \mathrm{~nm}$ for poly(Glu-Val-Lys-Val) did not change by the addition of TPPS, TPPS has no influence on the $\beta$-sheet structure of the polypeptide. 


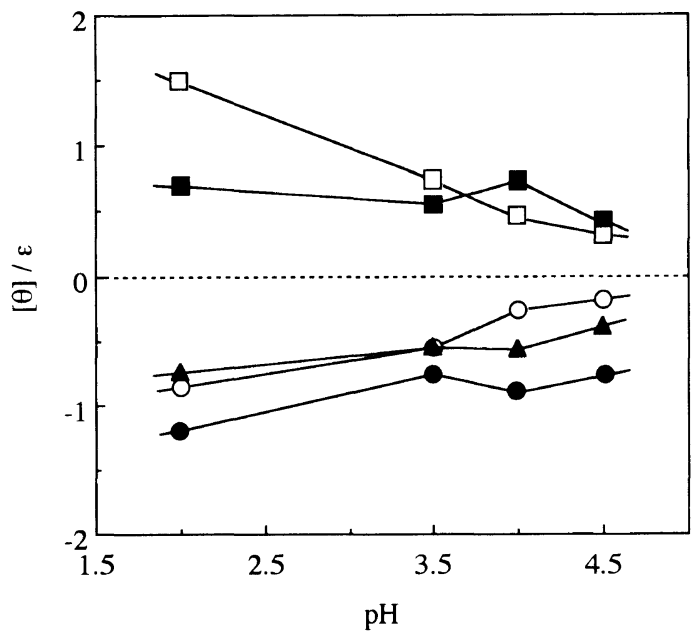

Figure 5. Dependence of $[\theta] / \varepsilon$ of the solutions of TPPS mixed with poly(Glu-Val-Lys-Val) on $\mathrm{pH}$ at $[\mathrm{P}] /[\mathrm{D}]=2$.

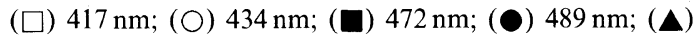
$705 \mathrm{~nm}$. Opened and closed symbols correspond to monomeric TPPS and aggregated TPPS, respectively.

\section{Dependence of Spectra of TPPS with Poly(Glu-} Val-Lys-Val) on $[P] /[D]$ Ratio

Figures 6 and 7 show the absorption spectra and induced $\mathrm{CD}$, respectively, of TPPS at $6.67 \times 10^{-5} \mathrm{M}$ mixed with poly(Glu-Val-LysVal) in aqueous solutions at $\mathrm{pH} 4.0$ at different $[\mathrm{P}] /[\mathrm{D}]$ ratios. Table II gives absorption parameters of wavelengths and molar extinction coefficients and CD parameters of the induced molar ellipticity for TPPS mixed with poly(Glu-Val-Lys-Val) at different $[\mathrm{P}] /[\mathrm{D}]$ ratios.

In the presence of poly(Glu-Val-Lys-Val) to $[\mathrm{P}] /[\mathrm{D}]=5$, absorption bands at $434 \mathrm{~nm}$ and $644 \mathrm{~nm}$ undergo hypochromism, and new bands at $489 \mathrm{~nm}$ and $701 \mathrm{~nm}$ appear and increase in magnitude with $[\mathrm{P}] /[\mathrm{D}]$ ratios. The CD spectra show a typical Davydov splitting around the absorption bands at $434 \mathrm{~nm}$ and $489 \mathrm{~nm}$, and both induced CD bands are composed of a positive band at shorter wavelength and negative band at longer wavelength. The induced CD band around $705 \mathrm{~nm}$ associated with the absorption band at $701 \mathrm{~nm}$ is observed and has one negatively band. The addition of poly(Glu-Val-Lys-Val) to a monomeric TPPS
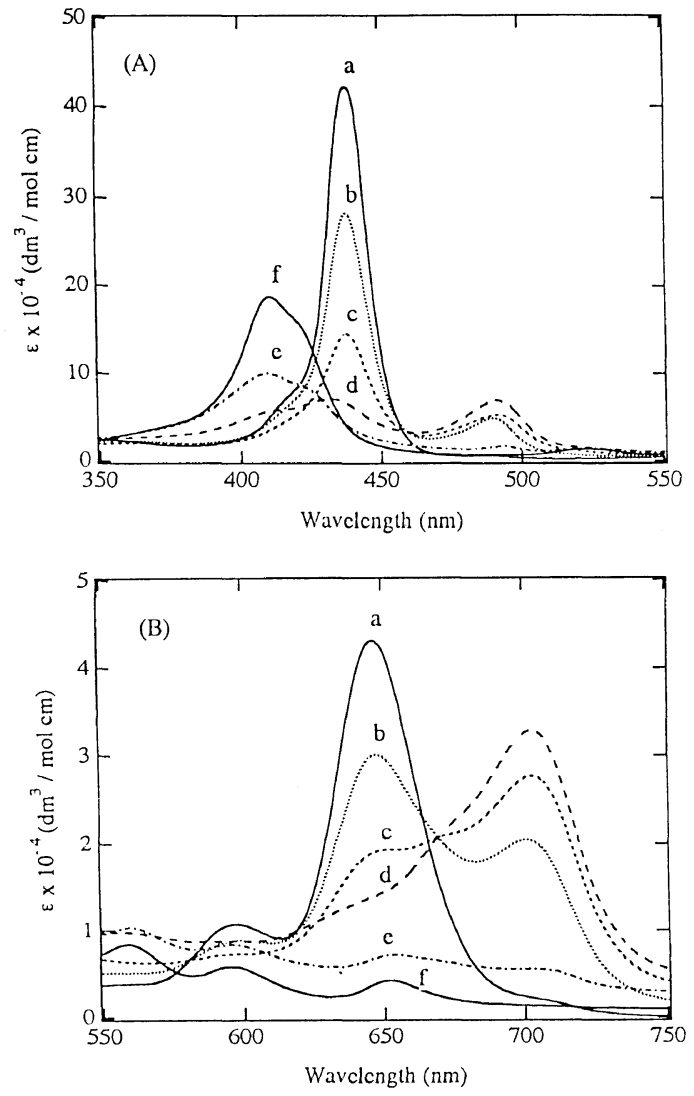

Figure 6. Absorption spectra of $6.67 \times 10^{-5} \mathrm{M}$ TPPS in aqueous solution at $\mathrm{pH} 4.0$ in the presence of poly(GluVal-Lys-Val) at different $[\mathrm{P}] /[\mathrm{D}]$ ratios. $[\mathrm{P}] /[\mathrm{D}]$ ratio: a, $0 ; \mathrm{b}, 1.0 ; \mathrm{c}, 2.0 ; \mathrm{d}, 5.0 ; \mathrm{e}, 10.0 ; \mathrm{f}, 20.0$. (A) wavelength, $350-550 \mathrm{~nm}$; (B) wavelength, $550-750 \mathrm{~nm}$.

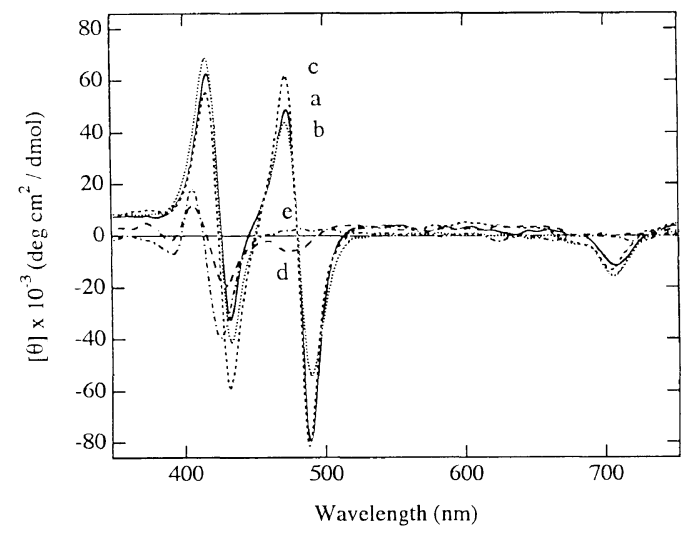

Figure 7. CD spectra of $6.67 \times 10^{-5} \mathrm{M}$ TPPS in aqueous solution at $\mathrm{pH} 4.0$ in the presence of poly(Glu-Val-Lys-Val) at different $[\mathrm{P}] /[\mathrm{D}]$ ratios. $[\mathrm{P}] /[\mathrm{D}]$ ratio: $\mathrm{a}, 1.0 ; \mathrm{b}, 2.0 ; \mathrm{c}$, $5.0 ; \mathrm{d}, 10.0 ; \mathrm{e}, 20.0$. 
diacid species may promote the formation of aggregation by preventing electrostatic repulsion between TPPS molecules with $\varepsilon$-ammonium groups of the polypeptide.

The dissymmetric factor, $[\theta] / \varepsilon$, of the CD bands corresponding to the absorption band at $434 \mathrm{~nm}$ is largest at $[\mathrm{P}] /[\mathrm{D}]=5$, whereas this factor of the CD band around $705 \mathrm{~nm}$ is largest at $[\mathrm{P}] /[\mathrm{D}]=1$ in shown Table II. At $[\mathrm{P}] /[\mathrm{D}]=5$, dissymmetric exciton coupling occurs most effectively for a monomeric TPPS diacid species, while exciton coupling may be induced most effectively for TPPS aggregation of the diacid species at $[\mathrm{P}] /[\mathrm{D}]=1$.

At $[\mathrm{P}] /[\mathrm{D}]$ ratios higher than 10 , the Soret band at $434 \mathrm{~nm}$ shifts to $406 \mathrm{~nm}$, and bands at $489 \mathrm{~nm}$ and $701 \mathrm{~nm}$ disappear. The absorption band at $406 \mathrm{~nm}$ is subject to hyperchromism with increasing $[\mathrm{P}] /[\mathrm{D}]$ ratio. Induced $\mathrm{CD}$ bands associated with the absorption band at $406 \mathrm{~nm}$ show exciton coupling and are composed of a positive band at shorter wavelength and negative band at longer wavelength. However, induced CD bands around $489 \mathrm{~nm}$ and $705 \mathrm{~nm}$ are not observed due to the disappearance of the corresponding absorption bands.

The absorption band at $406 \mathrm{~nm}$ is subject to blue-shift compared to the monomer bands of TPPS free base and diacid species, and exciton coupling is observed. Consequently, the band may be assigned to a different type of TPPS aggregated species (a dimer or an aggregate) from aggregation of TPPS diacid species described above. Because a blue-shift can be generally interpreted as due to face-to-face aggregation, TPPS may cause a face-to-face TPPS aggregation by the addition of the polypeptide above $[\mathrm{P}] /[\mathrm{D}]$ of 10 . The aggregation is $S$-chiral conformation from the results of polarity of the exciton coupling in analogy with aggregation of the TPPS diacid species. The hyperchromism indicates that the addition of poly(Glu-Val-Lys-Val) promotes formation of the face-to-face TPPS aggregation by strong electrostatic interactions between the polypeptide and aggregation of the TPPS diacid species.

At $\mathrm{pH}$ 4.0, TPPS exists as a monomeric diacid species in the absence of the polypeptide. A monomer and aggregation of TPPS diacid species are observed when $[\mathrm{P}] /[\mathrm{D}]$ is from 1

Table II. Absorption and CD parameters of TPPS in the presence of poly(Glu-Val-Lys-Val) ${ }^{\mathbf{a}}$

\begin{tabular}{|c|c|c|c|c|c|c|}
\hline & {$[\mathrm{P}] /[\mathrm{D}]=0$} & {$[\mathrm{P}] /[\mathrm{D}]=1$} & {$[\mathrm{P}] /[\mathrm{D}]=2$} & {$[\mathrm{P}] /[\mathrm{D}]=5$} & {$[\mathrm{P}] /[\mathrm{D}]=10$} & {$[\mathrm{P}] /[\mathrm{D}]=20$} \\
\hline $\begin{array}{c}\lambda, \mathrm{nm} \\
\left(10^{-3} \varepsilon, \mathrm{M}^{-1} \mathrm{~cm}^{-1}\right)\end{array}$ & $\begin{array}{l}434(385) \\
517(15.0) \\
595(10.9) \\
644(41.8)\end{array}$ & $\begin{array}{l}434(253) \\
487(47.6) \\
595(9.2) \\
644(29.2) \\
699(20.0)\end{array}$ & $\begin{array}{l}434(156) \\
489(60.2) \\
644(22.6) \\
701(27.5)\end{array}$ & $\begin{array}{l}428(70.7) \\
489(67.7) \\
644(13.5) \\
701(33.0)\end{array}$ & $\begin{array}{l}406(95.9) \\
555(10.6) \\
594(9.2) \\
651(6.7) \\
701(5.4)\end{array}$ & $\begin{array}{l}406(180) \\
554(8.8) \\
593(6.3) \\
648(4.6)\end{array}$ \\
\hline $\begin{array}{c}\lambda, \mathrm{nm} \\
\left(10^{-3}[\theta]\right. \\
\left.\operatorname{deg} \mathrm{cm}^{2} \mathrm{~d} \mathrm{~mol}^{-1}\right)\end{array}$ & & $\begin{array}{l}416(62.6) \\
432(-32.5) \\
473(48.9) \\
489(-79.7) \\
707(-11.7)\end{array}$ & $\begin{array}{l}416(68.5) \\
433(-41.3) \\
472(43.7) \\
490(-54.0) \\
706(-15.8)\end{array}$ & $\begin{array}{l}416(55.4) \\
432(-58.8) \\
473(61.5) \\
488(-81.5) \\
705(-13.4)\end{array}$ & $\begin{array}{l}406(11.4) \\
428(-19.4)\end{array}$ & $\begin{array}{l}406(18.0) \\
425(-39.6)\end{array}$ \\
\hline$[\theta] / \varepsilon$ & & $\begin{array}{r}0.25 \\
-0.13 \\
1.03 \\
-1.67 \\
-0.59\end{array}$ & $\begin{array}{r}0.44 \\
-0.26 \\
0.73 \\
-0.90 \\
-0.57\end{array}$ & $\begin{array}{r}0.78 \\
-0.83 \\
0.91 \\
-1.20 \\
-0.41\end{array}$ & $\begin{array}{r}0.12 \\
-0.20\end{array}$ & $\begin{array}{r}0.10 \\
-0.22\end{array}$ \\
\hline
\end{tabular}

${ }^{\mathrm{a}} \mathrm{pH}=4.0 ;[\mathrm{D}]=6.67 \times 10^{-5} \mathrm{M}$. 


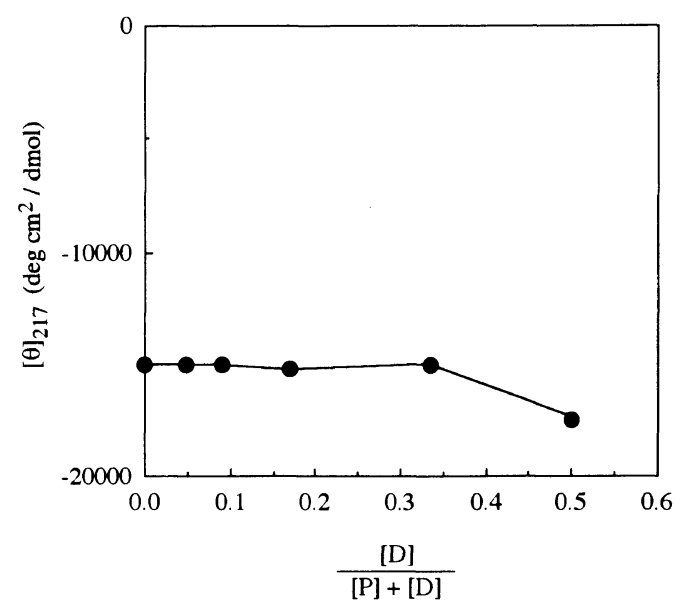

Figure 8. Dependence of molar ellipticity at $217 \mathrm{~nm}$ of poly(Glu-Val-Lys-Val) on $[\mathrm{P}] /[\mathrm{D}]$ ratios.

to 5 , in addition, the face-to-face TPPS aggregation above $[\mathrm{P}] /[\mathrm{D}]=10$. Consequently, TPPS aggregates by the addition of the polypeptide, and interconversion between two types of TPPS aggregation is observed by varying $[\mathrm{P}] /[\mathrm{D}]$ ratio from 5 to 10 . Chiral conformation of the two TPPS aggregations is the same.

Figure 8 shows the dependence of $\beta$-sheet content of poly(Glu-Val-Lys-Val) on $[\mathrm{P}] /[\mathrm{D}]$ ratio. Poly(Glu-Val-Lys-Val) forms $\beta$-sheet structure even in the presence of TPPS. $\beta$-sheet content is constant above $[\mathrm{P}] /[\mathrm{D}]=2$, but increases slightly at $[\mathrm{P}] /[\mathrm{D}]=1$. It is likely that Poly(Glu-Val-Lys-Val) crosslinks with TPPS by increasing interactions between TPPS and the polypeptide, and the polypeptide aggregates advantageously to take on the $\beta$-sheet structure. The polypeptide can form $\beta$-sheet structure more effectively than in the absence of TPPS.

Dependence of Spectra of TMPyP with Poly(Glu-Val-Lys-Val)

Absorption spectra of TMPyP in the absence of poly(Glu-Val-Lys-Val) are the same as those of in the presence of the polypeptide at various $[\mathrm{P}] /[\mathrm{D}]$ ratios and $\mathrm{pHs}$ (data not shown). In addition, induced CD bands are not observed under any conditions (data not shown). These results indicate that TMPyP cannot interact with poly(Glu-Val-Lys-Val). Because the lysine residue has a longer side chain than the glutamic acid residue, TMPyP has tendency to interact with the lysine residue rather than the glutamic acid residue. Accordingly, it is likely that TMPyP cannot interact with poly(GluVal-Lys-Val) due to electrostatic repulsion between the $N$-methylpyridinium groups and $\varepsilon$-ammonium groups of lysine residues in preference to electrostatic attraction between the $N$-methylpyridinium groups and the $\gamma$ carboxylic groups.

\section{DISCUSSION}

TPPS interacts with random coil or $\alpha$-helical poly(L-lysine) by electrostatic attraction between sulfonate groups of TPPS and $\varepsilon$-ammonium groups of poly(L-lysine) when TPPS exists as a free base species. ${ }^{13} \mathrm{~A}$ free base species of TPPS cannot bind to $\beta$-sheet poly(Glu-Val-Lys-Val), whereas its diacid species interacts with the polypeptide. These results suggest that the free base species has potential to interact with lysine residues of the polypeptide, but it is subject to electrostatic repulsion from $\gamma$-carboxylic groups of glutamic acid residues, while because the diacid species has positive charges in porphyrin center, this species has electrostatic attractive interaction between sulfonate groups and $\varepsilon$-ammonium groups as well as between their positive charges and $\gamma$-carboxylic groups. Therefore, positive charges may play a key role in formation of the TPPS-poly(Glu-Val-Lys-Val) complex.

The diacid species in aqueous solution at $\mathrm{pH}$ 4.0 is present in a monomeric state, but it aggregates to a dimer or aggregated species by formation of the TPPS-poly(Glu-Val-Lys-Val) complex. It is likely that the aggregation is responsible for the suppression of electrostatic repulsion between sulfonate groups of two TPPS molecules by lysine residues of the polypeptide. From $[\mathrm{P}] /[\mathrm{D}]=1$ to 5 , the ag- 
gregation has two specific absorption bands at $489 \mathrm{~nm}$ and $701 \mathrm{~nm}$, which would be face-to-face structure with closer $\pi-\pi$ interactions between two porphyrins by rotation of the phenyl groups of TPPS. Above $[\mathrm{P}] /[\mathrm{D}]=$ 10 , another type of aggregation with face-toface structure is observed, and this transformation between two aggregations may be due to increased electrostatic interactions between the polypeptide and TPPS with amount of polypeptide. It is likely that differences between these aggregations are due to different aggregation numbers or different shapes with the same aggregation number.

Binding of a diacid monomer and aggregated species to the polypeptide is more effective with decreasing $\mathrm{pH}$ because positive charges in porphyrin center increase and negatively charged glutamic acid residues by protonation of $\gamma$-carboxylic groups decrease with decreasing $\mathrm{pH}$. This would be caused by increase of electrostatic attraction between positive charges and glutamic acid residues as well as decrease of electrostatic repulsion between sulfonate groups and glutamic acid residues. The amount of aggregation increases with decreasing $\mathrm{pH}$ because electrostatic repulsion between sulfonate groups of TPPS molecules decreases by the positive charges.

On the other hand, because TMPyP interacts with poly(L-glutamic acid) by electrostatic interactions between $N$-methylpyridinium groups of TMPyP and $\gamma$-carboxylic groups of poly(L-glutamic acid), ${ }^{12}$ TMPyP seems to have potential to interact with poly(Glu-Val-LysVal), but TMPyP cannot interact with the polypeptide under experimental conditions. It is presumed that TMPyP cannot exist as a zwitterionic species such as a diacid species of TPPS, and the lysine residue has a longer side chain than glutamic acid residue. Thus, TMPyP cannot form a complex with the polypeptide by effective electrostatic repulsion between $N$-methylpyridinium and $\varepsilon$-ammonium groups.

Poly(Glu-Val-Lys-Val) is a zwitterionic polypeptide with a $\beta$-sheet structure, which in- teracts with a zwitterionic porphyrin derivative by two types of electrostatic attractive interactions. In addition, the polypeptide can induce to arrange the binding molecule dissymmetically. We suggest that poly(Glu-ValLys-Val)-TPPS complex may provide a generally useful model for studying the spatial arrangement and binding site of porphyrin derivatives bound to biological macromolecules.

Acknowledgments. The author thank Dr. M. Hirami of Unitika Ltd. for much helpful discussion and valuable comments on this work.

\section{REFERENCES}

1. U. Muller-Eberhard, in "Transport by Proteins," G. Blauer and H. Sund, Ed., Walter de Gruyter and Co., Berlin 1978, pp 295-308.

2. M. Calvin, Acc. Chem. Res., 11, 869 (1978).

3. J. H. Perrin and D. A. Nelson, J. Pharm. Sci., 25, 125 (1973).

4. L. Stryer and E. R. Blout, J. Am. Chem. Soc., 83, 1411 (1961).

5. M. Hatano, M. Yoneyama, Y. Sato, and Y. Kawamura, Biopolymers, 12, 2423 (1973).

6. M. K. Pal and M. Mandel, Biopolymers, 18, 2267 (1979).

7. J. E. Falk, in "Porphyrins and Metalloporphyrins," Elsevier, Amsterdam, 1964, Chapter 6, pp 72-93.

8. M. Gouterman, in "The Porphyrins Vol. 3, Physical Chemistry, Part A," D. Dolphin, Ed., Academic, New York, N.Y., 1978, pp 1-165.

9. R. F. Pasternack, P. R. Huber, P. Boyd, G. Engasser, L. Francesconi, E. Gibbs, P. Fasella, G. C. Venturo, and L. de C. Hinds, J. Am. Chem. Soc., 94, 4511 (1972).

10. E. B. Fleischer, J. M. Palmer, T. S. Srivastava, and A. Chatterjee, J. Am. Chem. Soc., 93, 3162 (1971).

11. S. Ikeda, T. Nezu, and G. Ebert, Biopolymers, 31, 1257 (1991).

12. T. Nezu and S. Ikeda, Bull. Chem. Soc. Jpn., 66, 18 (1993).

13. T. Nezu and S. Ikeda, Bull. Chem. Soc. Jpn., 66, 25 (1993).

14. Y. Fukushima, Polym. J., to be submitted.

15. K. M. Kadish, G. B. Maiya, C. Araullo, and R. Guilard, Inorg. Chem., 28, 2725 (1989).

16. K. Kano, T. Nakajima, M. Takei, and S. Hashimoto, Bull. Chem. Soc. Jpn., 60, 1281 (1987). 


\section{Y. Fukushima}

17. P. Doty, J. H. Bradbury, and A. M. Holtzer, J. Am. 21. T. K. Chandrashekar, H. van Willigen, and M. H. Chem. Soc., 78, 947 (1956). Ebsersole, J. Phys. Chem., 88, 4326 (1984).

18. T. Takamura, K. Konno, and H. Meguro, Anal. Sci., 1, 215 (1985).

22. N. Harada and K. Nakanishi, Acc. Chem. Res., 5, 257 (1972).

19. M. Gouterman, J. Chem. Phys., 30, 1139 (1959).

20. M. Gouterman, J. Mol. Spectrosc., 6, 138 (1961).

23. N. Harada, S. Suzuki, H. Uda, and K. Nakanishi, Chem. Lett., 67 (1972). 